\title{
As práticas em psicologia hospitalar e os afetos no profissional psi
}

\author{
The practices in hospital psychology and affections in the professional psy
}

Vanessa dos Santos Viveiro Medeiros ${ }^{\dagger *}$, Vanessa Mariano da Silva ${ }^{\dagger}$, Maria Clara de Mello Andrade

Como citar esse artigo. MEDEIROS, V.S.V.; DA SILVA, V.M.; ANDRADE, M.C.M. As práticas em psicologia hospitalar e os afetos no profissional psi. Revista Mosaico, v.11, n.1, p. 83$87,2020$.

\begin{abstract}
Resumo
A partir de pesquisa bibliográfica pretendeu-se expor a forma como se engendra a psicologia hospitalar no Brasil e refletir as maneiras que as vivências profissionais podem afetar $\mathrm{a}(\mathrm{o})$ psicóloga $(\mathrm{o})$, bem como o manejo frente às demandas que perpassam suas experiências pessoais. Primeiramente, aborda-se o contexto histórico em que a psicologia adentra o hospital tornando-se presente nesse espaço, fazendo então um paralelo entre as práticas profissionais, os afetos encontrados ali e os possíveis manejos que o psicólogo se utiliza para realizar seu trabalho. Conclui-se, portanto, refletindo que a dinâmica hospitalar perpassa muitas vezes as vivências do profissional e que este, por sua vez, precisa estar munido de instrumentos e autonomia para trabalhar as demandas que podem emergir neste lugar.
\end{abstract}

Palavras-chave: Psicologia hospitalar; práticas; afetos; demandas.

\section{Introdução}

Este artigo foi pensado a partir da experiência das autoras no estágio específico em psicologia hospitalar no curso de graduação em Psicologia, realizado num hospital universitário. O estágio objetivou aproximar os alunos da vivência profissional nos setores de oncologia, hemodiálise e enfermaria. Dessa forma, refletimos sobre a maneira em que as demandas do ambiente hospitalar afetam a(o) profissional psi, aquele que dentre suas práticas está intimamente ligado a demandar ao outro cuidado, acolhimento e escuta.

Comumente, vemos obras que debruçam seu enredo a partir das experiências do paciente no leito do hospital e elucidam a forma com que o profissional de saúde precisa operar nesse cenário. Manifesta- se, então, uma inquietação a questionar "como atuar quando estamos em frente a pacientes que nos remetem a vivências pessoais?" e, ainda, enquanto profissionais “é possível não se deixar afetar?".

No primeiro momento, retomamos os principais pontos do histórico da psicologia no ambiente hospitalar, suas precursoras e o modo com que foi implantada no Brasil. A seguir, vê-se a regulamentação pelo Conselho Federal de Psicologia (CFP) das práticas que o psicólogo hospitalar desempenha em sua função, ressaltando a necessidade de instrumentalização técnica-científica contínua ao longo de sua vida profissional. Por fim, alcançamos o principal tema do trabalho, que aponta para as maneiras possíveis de lidar com os afetos que entremeiam seu trabalho no hospital.

$\mathrm{O}$ artigo traz reflexões sobre a aproximação da relação psicólogo/paciente, entendendo que a matéria-

Afiliação dos autores:

${ }^{\dagger}$ Graduanda de Psicologia, Universidade de Vassouras, Vassouras, Rio de Janeiro, Brasil.

* Psicóloga, Mestre em Psicologia Social pela UERJ, Professora Assistente II da Universidade de Vassouras, Vassouras, Rio de Janeiro, Brasil.

*Email de correspondencia: vanessasantos_med@hotmail.com 
prima desse encontro é a subjetividade, ou seja, emoções, sentimentos próprios de cada indivíduo, e reitera sobre o lugar da(o) psicóloga(o) em cada atendimento.

Diante disso, foi realizada uma pesquisa bibliográfica, através da busca ativa de informações em livros, revistas e artigos acadêmicos, todos da área da Psicologia, em que foi possível elencar alguns aspectos gerais referentes à atuação da(o) psicóloga(o) hospitalar, conceitos e os afetos que a realidade do trabalho pode causar nesse profissional.

\section{A história da psicologia hospitalar no Brasil}

A psicologia no ambiente hospitalar tem seus primórdios, no Brasil, a partir da década de 1930, quando profissionais de saúde pensaram sobre fatores psicológicos atuarem no processo saúde doença; assim, instaurou-se a participação de psicólogas(os) como proposta às internações psiquiátricas dispensadas aos pacientes nos serviços de Higiene Mental, efetivando o exercício profissional nas instituições de saúde mental do Brasil (BRUSCATO; BENEDETTI; LOPES, 2004).

Em 1954, Matilde Neder iniciou o acompanhamento psicológico aos pacientes que eram submetidos a procedimentos cirúrgicos na Clínica Ortopédica e Traumatológica da Universidade de São Paulo (USP). Anos mais tarde, foi fundado por Bellkiss Wilma Romano o serviço de Psicologia do Instituto do Coração do Hospital das Clínicas, também na USP. A chamada psicologia hospitalar vai sendo esculpida, endereçando seu saber a diversas áreas dentro da unidade de saúde, cada uma com sua especificidade. (CAMON, 2004)

O fomentar desse campo na psicologia era de constante movimento, eclodindo na fundação da Sociedade Brasileira de Psicologia Hospitalar (SBPH) em 1997, por Romano e Moura, essa história é descrita no site da SBPH e tinha como objetivo desenvolver e fortalecer essa classe profissional no Brasil. A Psicologia Hospitalar foi regulamentada como especialidade nos anos 2000 pelo Conselho Federal de Psicologia (CFP).

A partir disso, o CFP define que a psicóloga(o) hospitalar cabe:

Atende a pacientes, familiares e/ou responsáveis pelo paciente; membros da comunidade dentro de sua área de atuação; membros da equipe multiprofissional e eventualmente administrativa, visando o bem-estar físico e emocional do paciente; e, alunos e pesquisadores, quando estes estejam atuando em pesquisa e assistência. Oferece e desenvolve atividades em diferentes níveis de tratamento, tendo como sua principal tarefa a avaliação e acompanhamento de intercorrências psíquicas dos pacientes que estão ou serão submetidos a procedimentos médicos, visando basicamente a promoção e/ou a recuperação da saúde física e mental. Promove intervenções direcionadas à relação médico/paciente, paciente/família, e paciente/ paciente e do paciente em relação ao processo do adoecer, hospitalização e repercussões emocionais que emergem neste processo. No trabalho com a equipe multidisciplinar, preferencialmente interdisciplinar, participa de decisões em relação à conduta a ser adotada pela equipe, objetivando promover apoio e segurança ao paciente e família, aportando informações pertinentes à sua área de atuação, bem como na forma de grupo de reflexão, no qual o suporte e manejo estão voltados para possíveis dificuldades operacionais e/ ou subjetivas dos membros da equipe. (CFP, 2007, p. 21).

A Psicologia Hospitalar transita por diversas possibilidades de trabalho dentro das instituições. Simonetti (2004), de maneira conceitual, ainda define como "campo de entendimento e tratamento dos aspectos psicológicos em torno do adoecimento". O autor aponta para os aspectos psicológicos como objeto do trabalho da Psicologia Hospitalar, todavia, indicando a presença da subjetividade em toda doença, permitindo compreendêla pelo âmbito biopsicossocial; sendo assim, "oferece caminhos para uma prática na promoção de saúde mais voltada para o paciente, portanto, menos voltada para o sintoma ou para doença." (RODRIGUES; FRANÇA, 2010).

A realidade do adoecimento pode objetificar o sujeito, tornando-o passivo à prática hospitalar, passando a ser alvo de atenção e intervenção, transformando a posição que antes ocupava de sujeito de intenção, isto é, dotado de singularidades. Sendo assim, o indivíduo se perde de seus referenciais construídos ao longo da vida, tendo suas vontades aplacadas ao adentrar na dinâmica da instituição, configurando, muita das vezes: abandono, isolamento, rompimento de relações afetivas importantes no âmbito profissional e social. (ROSSI, 2007).

Deste modo, a psicologia hospitalar atenta ao paciente para além do adoecer, compreendendo que a hospitalizaçãotambémé condicionante para o surgimento de sentimentos dolorosos (NIGRO, 2004). Posto isto, $\mathrm{a}(\mathrm{o})$ psicóloga(o) objetiva dar voz à subjetividade, o que proporciona ao doente uma proximidade com o seu sofrimento, de maneira a criar recursos simbólicos frente ao adoecimento e, principalmente, validar as emoções que surgem na tentativa de adaptação a esse cenário inesperado. (SOUZA; MOURA; CORRÊA, 2009).

\section{As práticas da psicologia hospitalar}

Estar inserido no contexto hospitalar requer um conhecimento teórico específico do profissional de psicologia, por se tratar de um ambiente de atuação dinâmico e peculiar; por isso, estar preparado teoricamente é fundamental para o embasamento prático do trabalho que será realizado, além de ser um compromisso ético, visto que, dentre as normativas, o CFP $(2005$, p. 9) propõe que "o psicólogo atuará com 
responsabilidade, por meio do contínuo aprimoramento profissional, contribuindo para o desenvolvimento da psicologia como campo científico de conhecimento e de prática". Sabendo-se que cada instituição possui uma realidade, é necessário identificar as demandas para assim estabelecer uma linha de trabalho que possibilite uma relação instituição-profissional-paciente.

Segundo Rocha (2004), a atenção da(o) psicóloga(o) volta-se à relação do paciente com a família, com a equipe profissional e com a instituição de saúde. Esse conjunto influencia intrinsecamente a subjetividade do paciente na elaboração simbólica da realidade do adoecimento. Posto isto, destaca-se que "[...] o êxito não significa acertar um diagnóstico da psicopatologia do paciente que, de fato, sempre em maior ou menor grau, etiológica ou reativamente existe, mas respeitar a natureza do enquadre selecionado pelo paciente" (FERRARI; LUCHINA; LUCHINA, 1971). Sendo esse enquadre o objeto de trabalho da(o) profissional psi, em que proporcionará a escuta dos sentimentos e atitudes do paciente enfermo física e psicologicamente, portanto, “o psicólogo hospitalar participa dessa travessia como ouvinte privilegiado, não como guia" (SIMONETTI, 2004).

No primeiro momento, o paciente é acolhido com seu relato ainda que este pareça não ter relação direta com o tratamento e o diagnóstico; mesmo assim, é necessário auxiliar de maneira que possibilite reconstruir e respeitar as razões que expressa serem a causa de seu adoecimento e, principalmente, a ligação que é capaz de fazer entre o que sente e seus modos de vida, podendo trazer nas entrelinhas emoções e desafetos. $\mathrm{O}$ acolhimento viabiliza uma criação de vínculo entre a(o) psicóloga(o), o paciente e a família (SCHNEIDER; MANSCHEIN; AUSEN, 2008).

Nesse ponto, a(o) psicóloga(o) precisa dirigir uma escuta atenta ao paciente, sendo preciso "uma economia de gestos e palavras, um silêncio ativo e um certo reconhecimento, evidenciando uma postura de acolhimento às reais necessidades do outro" (ARANTES, 2008), compreendendo, sem fazer présuposições de que a demanda de sofrimento sentida seja irreal ou exagerada, permitindo-se ouvir.

Durante a hospitalização é comum ascender conflitos, devido ao afloramento das emoções, frente às mudanças que o adoecimento causa na estrutura familiar estabelecida anteriormente. Então, será papel da psicóloga apoiar na redefinição de papéis, buscando assim o alivio emocional, compreendendo que esses familiares também podem sofrer com as incertezas sobre o futuro do paciente e isso se acentua quando este é o provedor de recursos (MOREIRA; MARTINS; CASTRO, 2012)

Dessa forma, a psicóloga hospitalar facilita o fluxo das emoções, intervindo no foco da ansiedade e das dúvidas, a fim de promover incentivo ao vínculo com a equipe de saúde, tendo em vista que a participação efetiva da família colabora diretamente para a aceitação do paciente quanto ao tratamento (MENDES; LUSTOSA; ANDRADE, 2009).

No setting hospitalar, o manejo do psicoterapeuta é de extrema importância, visto que, por se tratar de um contexto adverso, em que não há privacidade para $\mathrm{o}$ atendimento psicológico, esse muitas vezes acontece à beira do leito ou pelos corredores. Sabendo-se, ainda, que seu trabalho poderá ser interrompido, adiantado ou cancelado, é preciso manter uma postura flexível, disposta a adaptar-se de maneira racional e que garanta a colaboração junto à equipe multidisciplinar, objetivando a aderência ao tratamento (PENNA, 1992).

\section{A(O) psicóloga(o) hospitalar e os seus afetos}

Nesse ponto, nos propomos refletir acerca da forma com que as vivências, na atuação do profissional, afetam $\mathrm{a}(\mathrm{o})$ psicóloga(o) hospitalar e o lugar que elas ocupam no modo de operar com o saber técnico-científico. No hospital, a psicóloga dispõe sua escuta, objetivando o alívio do sofrimento; por isso, permite o paciente "falar de si, da doença, da família, de seus medos, fantasias, esclarecendo suas dúvidas" (CAMPOS, 1995). Dessa forma, se dá o acolhimento da demanda.

Então, abrimos espaço para discutir os efeitos de uma intervenção que para Lourau (1975), dentre outras coisas, significa "articular lacunas, ver relações onde só se percebiam elementos coerentes e homogêneos, comprovar um problema onde se julgava existirem soluções", isto é, suspender, questionar, os modos naturalizados e instituídos e a partir dessa análise suscitar diferentes maneiras de intervenção.

Para prosseguirmos, nos deteremos em dois conceitos importantes, implicação e sobreimplicação. Coimbra e Nascimento (2007) trazem a noção de que estamos implicados a todo tempo, ou seja, a implicação independe de nossa escolha consciente, está no mundo, nas nossas relações. O ponto chave é o que podemos chamar de análise de implicação; em outras palavras, remete ao processo de desnaturalização do que está posto, nos convocando a afirmar as multiplicidades, potencializar os encontros e construção histórica dos sujeitos. Ainda, a sobreimplicação resume-se em considerar uma única fonte de saber ou informação, remetendo a impossibilidade de fazer emergir outras esferas para que sejam pensadas. Ainda pela perspectiva das autoras, estar sobreimplicado é condescender com a fragilização do coletivo e, com a repetição das práticas institucionalizadas num emaranhado de urgências, em que tarefas se acumulam, perder- se de si mesmo.

Tendo em vista esse contexto, no ambiente hospitalar pode ser identificada uma grande dificuldade 
em acolher as demandas do paciente, por parte do profissional psi, e isso pode acontecer, seja por sentimentos de incapacidade frente ao paciente crônico, seja por experiências pessoais semelhantes ao longo da vida. É de suma importância construir estratégias de defesa para auxiliarem em situações de afeto como estas. (MENDES; LUSTOSA; ANDRADE, 2009).

Mello (1999), questiona "será possível olhar as pessoas, sentir o cheiro das gentes, molhar-se nas águas da pobreza das ruas e ainda assim estar falando de psicologia?" A autora faz ascender uma reflexão em relação à forma como se deu o início da prática da psicologia, estruturada na neutralidade científica. Numa lógica objetiva, na realidade do hospital, em que vai ao encontro do paciente, $\mathrm{a}(\mathrm{o})$ psicóloga(o) tende a esvaziarse de suas vivências pessoais para que o paciente, então, possa lançar suas demandas com êxito.

Nas décadas de 1950 e 1960, diversos movimentos profissionais iniciaram a defesa do saber implicado e refletido, compreendendo que ser afetado pelos encontros é uma condição inerente às relações do indivíduo com o mundo. Portanto, faz-se necessário sair da superficialidade e colocar em análise as implicações e também as práticas sobreimplicadas, de maneira a suspender diferentes possibilidades de enfrentamento, forças e movimentos que antes não pensávamos existir em nós. "Aqui, interessa a apropriação da capacidade de movimentar-se, a possibilidade de sempre transitar, de ignorar cercas, rearrumar e criar outros territórios" (COIMBRA; LEITÃO, 2003).

Nessa perspectiva, a psicologia frente ao paciente hospitalizado permite-se afetar pelos ruídos, falas e gestos, pela aproximação dos corpos, pelo olfato, pelas cores. Percebe que seu papel é para além de resoluções imediatas, é um constante constituir-se nas relações, àquele que, ao intervir, se reconhece como sujeito de demandas. (FREIRE, 1997).

\section{Considerações Finais}

A psicologia hospitalar faz uma interseção entre a instituição, família e paciente por entender que todos estão implicados e que os impactos experienciados ali são, muitas vezes, devastadores, tanto para aqueles que são acometidos pelo diagnóstico, quanto para os acompanhantes de alguém que adoece, e isso pode tornar- se ainda mais delicado quando os indivíduos se deparam com a possibilidade de perder sua autonomia.

O dinamismo da hospitalização, é capaz de erguer emoções bem adversas porque a mudança a ser encarada, pode acontecer de forma abrupta. Exigindo uma nova construção psíquica, que possibilite outras formas de enfrentamento e, principalmente, reconhecerse em meio à descaracterização que pode vir a ocorrer no adoecimento.
Neste momento, a(o) psicóloga(o) hospitalar terá o papel de auxiliar na recuperação de um sentido de vida, baseando-se em uma relação de confiança, objetivando o vínculo, tendo em mente que o seu trabalho repercutirá na aderência do paciente ao tratamento.

É importante ressaltar que todo atendimento se dá pela aproximação da(o) psicóloga(o) ao paciente, visando, a partir do acolhimento e da escuta intervir de forma a ressignificar toda angústia que pode ser suscitada nesse cenário.

Contudo, espera-se que esse artigo demonstre a importância da presença da(o) psicóloga(o) no hospital, considerando que este lugar propicia diferentes emoções a todos que estão inseridos, inclusive os profissionais de saúde. Portanto, entende-se que os afetos se dão de forma involuntária, ou seja, a(o) profissional psi sempre será tocado pela demanda que é apresentada no atendimento, o que realmente parece interessar é a maneira em que se dá o gerenciamento das emoções. Neste contexto, $\mathrm{a}(\mathrm{o})$ psicóloga(o), tendo em vista todo seu aparato científico, entende que o paciente é aquele a quem direciona seu trabalho, por isso, em constante análise de implicação estará atento a seus próprios afetos e os levará a serem trabalhados em sua supervisão ${ }^{1}$ também com profissional da psicologia, sendo assim, volta-se ao atendimento com o paciente, podendo transitar entre as demandas e desbravar possibilidades de intervir

\section{Notas}

1. Buys (1987) refere-se à supervisão em psicologia, como essencial para a prática $\mathrm{da}(\mathrm{o})$ psicóloga(o), pois é o espaço em que a(o) profissional pode refletir as demandas que chegam para o atendimento a partir do encontro com outras(os) profissionais da psicologia.

\section{Referências}

ARANTES, E. M. M. Mediante quais práticas a psicologia e o direito pretendem discutir a relação? Anotações sobre o mal-estar. In C. Coimbra, L. Ayres \& M. L. Nascimento (Orgs.), Pivetes: encontro entre a psicologia e o judiciário. Curitiba: Juruá, 2008.

BRUSCATO, W. L. BENEDETTI, C.; LOPES, R. S. A. A prática de Psicologia Hospitalar na Santa Casa de São Paulo: novas páginas em uma história antiga. São Paulo: Casa do Psicólogo, 2004.

BUYS, R. C. Supervisão de psicoterapia: a abordagem humanista centrada na pessoa. São Paulo: Summus, 1987

CFP. Conselho Federal de Psicologia. Código de Ética Profissional do Psicólogo, Brasília: CFP, 2005.

CFP. Conselho Federal de Psicologia. Resolução Administrativa/Financeira $\mathrm{n}^{\circ}$. 15, de 19 de setembro de 2007. Brasília: CFP, 2007

CAMON, V.A. Tendências em psicologia hospitalar. São Paulo: Thompson, 2004.

CAMPOS, F. C. B. Considerações Sobre o Movimento de Reforma dos Serviços de Saúde Mental. In M. J. Spink (org.) Psicologia e Saúde: Repensando Práticas. São Paulo: EPU, 1995.

COIMBRA, C. M. B; LEITÃO, M. B. S. Das essências às multiplicidades: especialismo psi e produções de subjetividades. Psicol. Soc. [online], v. 15 , n. 2, p. 6-17, 2003. Disponível em: https://doi.org/10.1590/S010271822003000200002 . Acesso em: 18 mar 2020. 
COIMBRA, C. M. B.; NASCIMENTO, M. L. Sobreimplicação: práticas de esvaziamento político? In: ARANTES, E. M. M; NASCIMENTO, M. L.; FONSECA, T. M. G. (orgs.), Práticas psi inventando a vida. Niterói: EdUFF, 2007. p. 27-38. Disponível em: https://app.uff.br/slab/uploads/texto22.pdf. Acesso em: 19 mar 2020.

FERRARI, M.; LUCHINA, J; LUCHINA, N. La interconsulta médicopsicológica em el marco hospitalario. Buenos Aires: Nueva Vision, 1971.

FREIRE, P. Pedagogia da Autonomia: saberes necessários à prática educativa. São Paulo: Paz e Terra, 1997.

LOURAU, R. Análise Institucional. Petrópolis: Vozes, 1975.

MELLO, S. L. Prefácio. In BATISTA, L.A. A cidade dos sábios. São Paulo: Summus, 1999.

MENDES, J. A.; LUTOSA, M. A.; ANDRADE, M. C. M. Paciente Terminal, Família e Equipe de Saúde. Sociedade Brasileira de Psicologia Hospitalar, Rio de Janeiro, v. 12, n. 1, p. 151-173, jun. 2009. Disponível em: http://pepsic.bvsalud.org/scielo.php?script=sci_arttext \&pid=S151608582009000100011. Acesso em: 20 nov. 2019.

MOREIRA, E. K. C. B.; MARTINS, T. M.; CASTRO, M. M. Representação social da Psicologia Hospitalar para familiares de pacientes hospitalizados em Unidade de Terapia Intensiva. Sociedade Brasileira de Psicologia Hospitalar, Rio de Janeiro, v. 15, n. 1, p. 134-162, jun. 2012. Disponível em: http://pepsic.bvsalud.org/scielo.php?script=sci_arttext\&pid=S151608582012000100009. Acesso em: 17 mar 2020.

NIGRO, M. Hospitalização: o impacto na criança, no adolescente e no psicólogo hospitalar. São Paulo: Casa do Psicólogo, 2004.

PENNA, A. G. A História da Psicologia no Rio de Janeiro. Rio de Janeiro: Imago, 1992.

ROCHA J. J. R. Psicohansenologia: um estudo psicológico da hanseníaseestresse, medo, estigma e crença em pacientes e equipes de saúde em São Luís do Maranhão. Tese de Doutorado. Pontifícia Universidade Católica de São Paulo. São Paulo, 2004.

RODRIGUES, A. L.; FRANÇA, A. C. L. Uma perspectiva psicossocial em psicossomática via estresse e trabalho. MELLO FILHO, J.; BURD, M. (orgs.). Psicossomática hoje. Porto Alegre: Artmed, 2010.

ROSSI, L. Psicologia e emergências médicas. In: Lucia, M. C. S., \& Quayle, J. (Orgs.). Adoecer: as interações do doente com sua doença. 2a ed. São Paulo: Editora Atheneu, 2007.

SCHNEIDER, D. G.; MANSCHEIN, A. M. M.; AUSEN, M. A. B. Acolhimento ao paciente e família na unidade coronariana. Texto ContextoEnferm, Florianópolis, v. 17, n. 1, janeiro, p. 81-89,2008. Disponível em: http:// www.scielo.br/scielo.php?pid=S0104-07072008000100009\&script $=$ sci abstract\&tlng=pt. Acesso em: 17 mar 2020.

SIMONETTI, A. Manual de psicologia hospitalar: o mapa da doença. São Paulo: Casa do Psicólogo, 2004.

SOUZA, A. M.; MOURA, D. S. C.; CORRÊA, V. A. C. Implicações do pronto atendimento psicológico de emergência aos vivenciam perdas significativas. Psicologia Ciência e profissão, Brasília, v. 29, n. 3, p. 534545, fev. 2009. Disponível em: http://www.scielo.br/scielo.php?pid=S141498932009000300008\&script=sci_arttext\&tlng=pt. Acesso em: 13 mar 2020 . 